
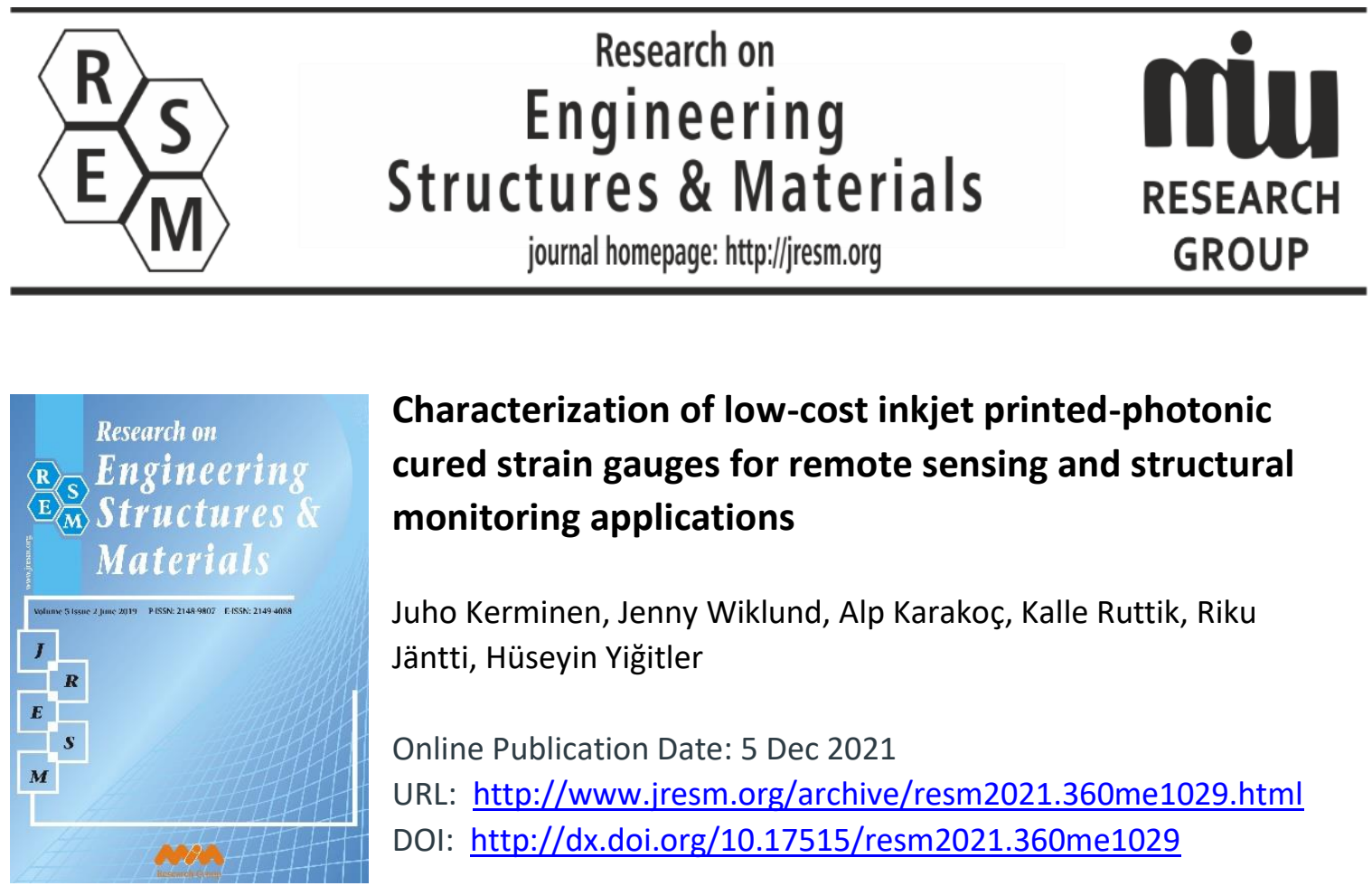

\title{
Characterization of low-cost inkjet printed-photonic cured strain gauges for remote sensing and structural monitoring applications
}

Juho Kerminen, Jenny Wiklund, Alp Karakoç, Kalle Ruttik, Riku Jäntti, Hüseyin Yiğitler

Online Publication Date: 5 Dec 2021

URL: http://www.jresm.org/archive/resm2021.360me1029.html

DOI: http://dx.doi.org/10.17515/resm2021.360me1029

Journal Abbreviation: Res. Eng. Struct. Mater.

\section{To cite this article}

Kerminen J, Wiklund J, Karakoç A, Ruttik K, Jäntti R, Yiğitler H. Characterization of low-cost inkjet printed-photonic cured strain gauges for remote sensing and structural monitoring applications. Res. Eng. Struct. Mater., 2021; 7(4): 647-660.

\section{Disclaimer}

All the opinions and statements expressed in the papers are on the responsibility of author(s) and are not to be regarded as those of the journal of Research on Engineering Structures and Materials (RESM) organization or related parties. The publishers make no warranty, explicit or implied, or make any representation with respect to the contents of any article will be complete or accurate or up to date. The accuracy of any instructions, equations, or other information should be independently verified. The publisher and related parties shall not be liable for any loss, actions, claims, proceedings, demand or costs or damages whatsoever or howsoever caused arising directly or indirectly in connection with use of the information given in the journal or related means.

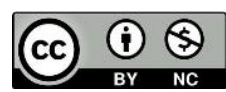

Published articles are freely available to users under the terms of Creative Commons Attribution - NonCommercial 4.0 International Public License, as currently displayed at here (the "CC BY - NC"). 


\title{
Research on Engineering Structures \& Materials
}

journal homepage: http://jresm.org

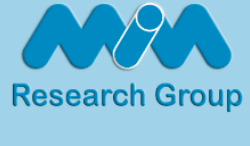

Research Article

\section{Characterization of low-cost inkjet printed-photonic cured strain gauges for remote sensing and structural monitoring applications}

\author{
Juho Kerminen ${ }^{1, a}$, Jenny Wiklund ${ }^{2, b}$, Alp Karakoç,c, Kalle Ruttik ${ }^{1, d}$, Riku Jäntti1,e, \\ Hüseyin Yiğitler ${ }^{1, \mathrm{f}}$ \\ ${ }^{1}$ Department of Communications and Networking, Aalto University, 02150 Espoo, Finland \\ ${ }^{2}$ Department of Bioproducts and Biosystems, Aalto University, 02150 Espoo, Finland
}

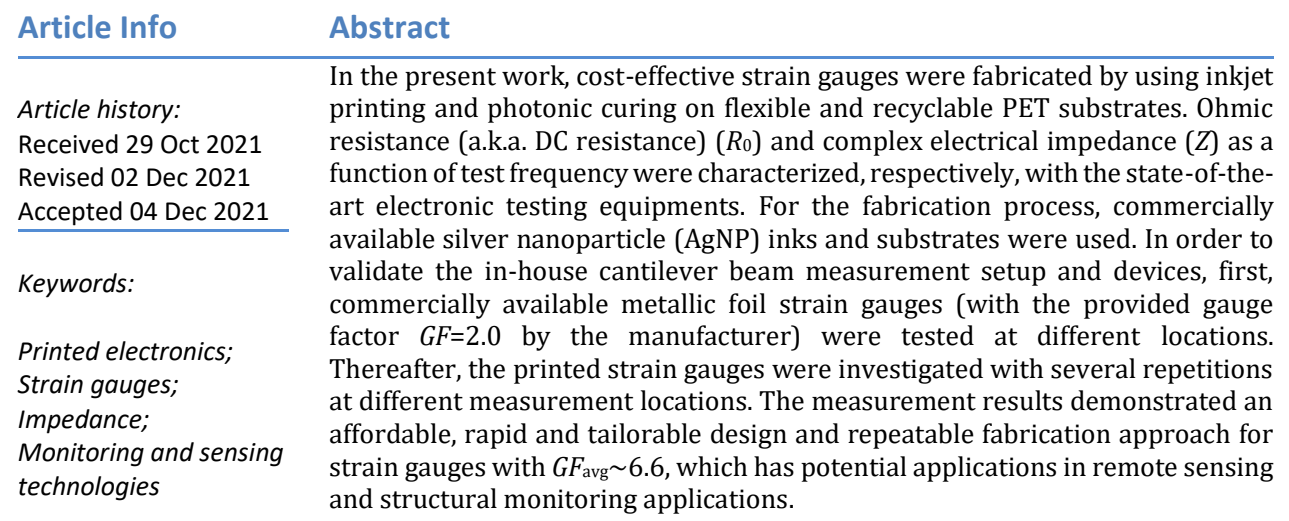

(C) 2021 MIM Research Group. All rights reserved.

\section{Introduction}

Strain gauges are electromechanical sensing devices created from thin conductive lines on top of a rigid or flexible substrate, which are then attached to the measurement region [1, 2]. The resistance, capacitance, impedance or piezoelectric characteristics of such devices change when the measurement region is subject to any source of deformation $[3,4]$. They can be fabricated by depositing metallic film onto substrates, photolithography, screen printing, aerosol or inkjet printing, to name a few $[5,6,7]$. Due to their cost-effectiveness, tailorable design, high bendability and stretchability, flexible printed strain gauges have been gaining grounds, e.g. in healthcare applications, wearable device technologies, structural health monitoring and intelligent packaging solutions $[8,9,10]$.

Despite their advantages and applicability, their electromechanical characteristics may vary a lot due to the fabrication processes, for which the micro-structural variations and fabrication repeatability play critical roles. For instance, in case of inkjet printing, which is based on deposition of ink droplets to create conductive traces with, e.g. silver (Ag) or copper (Cu) nanoparticles (NPs), porosity, thickness and roughness at the boundaries of the traces have dominant effect on both electrical and mechanical characteristics of the designed devices $[11,12,13]$. To be able to improve such characteristics, e.g. strength and electrical conductivity, multiple layers of deposition and sintering methods have been proposed and widely applied in the literature $[14,15]$. It has been observed that sintering

\footnotetext{
*Corresponding author: alp.karakoc@aalto.fi

a orcid.org/0000-0003-0394-4704; b orcid.org/0000-0001-6617-8846; c orcid.org/0000-0002-2010-9607;

d orcid.org/0000-0002-7365-9194; e orcid.org/0000-0002-5398-2381; ${ }^{\text {f }}$ orcid.org/0000-0002-7794-2763 DOI: http://dx.doi.org/10.17515/resm2021.360me1029
}

Res. Eng. Struct. Mat. Vol. 7 Iss. 4 (2021) 647-660 
effectively agglomerate NPs by densifying and bonding them together while deposition of multiple layers increases the thickness of the conductive traces; hence, the electrical conductivity $[16,17]$.

Traditionally, strain gauges are fabricated as metallic foils arranged in grid patterns and used in Wheatstone bridge configuration. The bridge usually measures the DC voltage change on the strain gauge exposed to the applied loads $F$. For the metallic foil strain gauges, it is sufficient to characterize the initial reference ohmic resistance (a.k.a. DC resistance) $R_{0}$ and gauge factor $(G F)$, which expresses the sensitivity of the strain gauge, as the resistance change $\Delta R=R-R_{0}$ with respect to $R_{0}$ and strain $\varepsilon$, i.e. [18]

$$
G F=\frac{\Delta R / R_{0}}{\varepsilon}
$$

For off-the shelf commercial strain gauges, $G F \sim 2.0$ is quite common while higher values have been achieved, e.g. $G F \sim 3.0$ and $G F \sim 5.0$ with inkjet printing by Rahman et al. and Kravhcuk et al., respectively [19, 20, 21]. Nevertheless, variations exist in electrical characteristics of the printed strain gauges with the frequency shifts when they are deformed as a result of $F$. These changes can be explained with the uneven distribution of the conductive ink of the printed patterns resulting in microscopic inductance $(L)$ and capacitance $(C)$ changes subjected to $F$. Hence, this means that the printed strain gauge may function as resonant (LC) circuit with its specific resonant frequency $\omega_{r}$. Therefore, in addition to $R_{0}$, frequency response $\omega$ and frequency dependent impedance of printed strain gauges $Z(\omega)=R(\omega)+j X(\omega)$, which is composed of resistance $R(\omega)$ and reactance $X(\omega)$ , should be measured. Such characterization is especially useful for matching the impedance with the circuitry used in passive strain gauge measurement telemetry system, through which the strains can be remotely read [22, 23, 24].

The current study presents a framework for the fabrication and characterization of novel printed strain gauge design, which can function as resonant (LC) circuit and has prospective uses in remote sensing and structural monitoring. For the fabrication process, low-cost inkjet printing equipment was used and the effect of process parameters including number of deposited layers, i.e. trace height, and sintering, which was realized with photonic curing in the present study, on the conductivity was investigated. For the electromechanical characterization, a cantilever beam structure and an impedance analyzer were used to understand the frequency response of the printed strain gauges within the range of $0-500 \mathrm{MHz}$ as function of $\varepsilon$ due to $F$ and to compute $\omega$, which was around $200 \mathrm{MHz}$ for the present design. Therefore, it was possible to compute reliable $G F$ values by means of the defined frequency bandwidth of $49-50 \mathrm{MHz}$, which was a distant range from $\omega_{r}$. For the validation of the characterization setup and comparison with the printed strain gauges, commercially available metallic foil strain gauges were used. The validation and comparison studies demonstrated that the printed strain gauges were promising with the $G F \sim 6.6$ while the commercial ones were measured to have $G F \sim 1.8$ , out of which $10 \%$ measurement error was deduced (in comparison with the provided $G F=2.0$ by the manufacturer). 


\section{Materials and Methods}

\subsection{Design, Fabrication of Low-Cost Printed and Photonic Cured Strain Gauges}

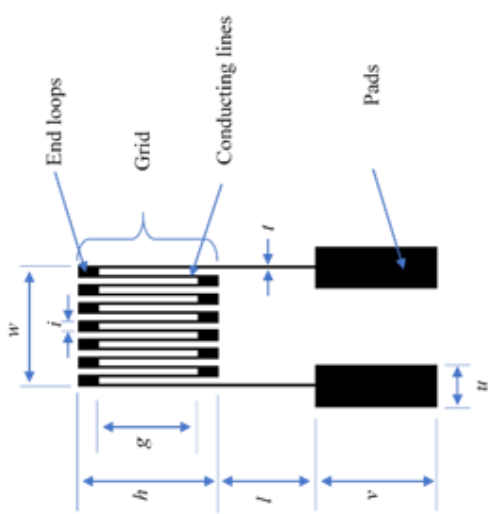

\begin{tabular}{|c|c|}
\hline Parameter & Value \\
\hline Number of conducting lines & 14 \\
\hline Ink & $\begin{array}{l}\text { Mitsubishi NBSIJ-MU01 } \\
\text { Ag nanoparticle content: } 15 \% \\
\text { Ag nanoparticle diameter: } 20 \mathrm{~nm}\end{array}$ \\
\hline Substrate & $\begin{array}{l}\text { Mitsubishi NB-TP-3GU100 } \\
\text { Thickness: } 135 \mu \mathrm{m} \\
\text { Heat resistance: Max. } 120^{\circ} \mathrm{C}\end{array}$ \\
\hline Printer/printer settings & $\begin{array}{l}\text { Epson C88+ inkjet printer } 5760 \times 1440 \text { dpi } \\
\text { Matte, Heavyweight } \\
\text { Grayscale } \\
\text { Best Photo } \\
\text { Low speed }\end{array}$ \\
\hline Curing & $\begin{array}{l}\text { Photonic curing, custom device } \\
\text { Linear } 400 \mathrm{~mm} \text { Reflector XFTR-L400C } \\
\text { (1500W XenonFlash) } \\
15 \text { seconds for each layer }\end{array}$ \\
\hline Number of printed layers & 3 \\
\hline Grid line (trace) thickness, $b$ & $\sim 0.4$ micron $[1]$ \\
\hline Gage length, $g$ & $27 \mathrm{~mm}$ \\
\hline Grid height, $h$ & $34 \mathrm{~mm}$ \\
\hline End loop width, $i$ & $2 \mathrm{~mm}$ \\
\hline Transition, $l$ & $15 / 20 / 25 \mathrm{~mm}$ \\
\hline Grid width, $w$ & $20 \mathrm{~mm}$ \\
\hline Grid line (trace) width, $t$ & $\sim 0.35 \mathrm{~mm}$ \\
\hline Pad width, $u$ & $7 \mathrm{~mm}$ \\
\hline Pad height, $v$ & $21 \mathrm{~mm}$ \\
\hline
\end{tabular}

Fig. 1 Geometric and fabrication process parameters of the inkjet printed strain gauge

The strain gauge pattern as designed and represented in Fig. 1 were parametrically created in Mathematica technical computing software and transferred as scalable vector graphics (.svg) to Inkscape open-source drawing software. The generated files were printed onto A4 size Mitsubishi NB-TP-3GU100 transparent polyethylene terephthalate (PET) special media, which has microporous $\mathrm{Al}_{2} \mathrm{O}_{3}$-PVA single-sided coating and sheet thickness of $135 \pm 12 \mu \mathrm{m}$. The conductive ink used on the NB-TP-3GU100 special media was Mitsubishi NBSIJ-MU01 silver nanoparticle (AgNP) inkjet printer ink, which was also purchased from Mitsubishi Paper Mills Ltd. The ink was loaded to the black ink cartridge of Epson Stylus C88+ inkjet printer (5760 dpi x 1440 dpi resolution) (please, see Fig. 2) with the following printer software settings: "Matte Paper - Heavyweight", "best photo" and "gray scale". For 
increasing the print quality and registration for the special media and AgNP ink, "High speed printing" option was set off.

(a)

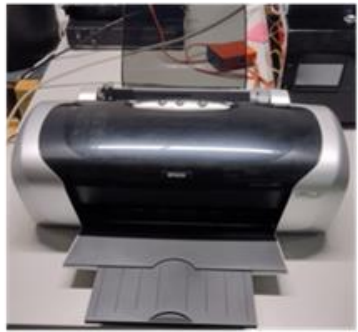

(c)

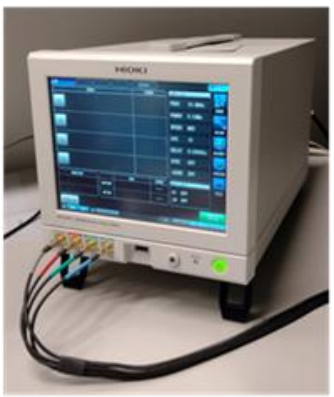

(b)

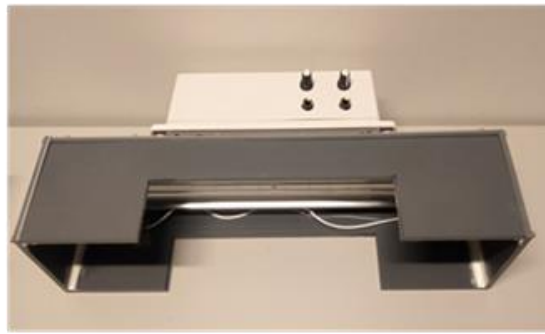

(d)

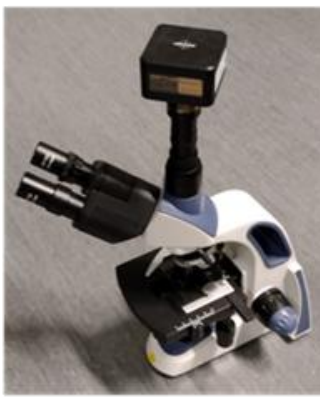

(e)
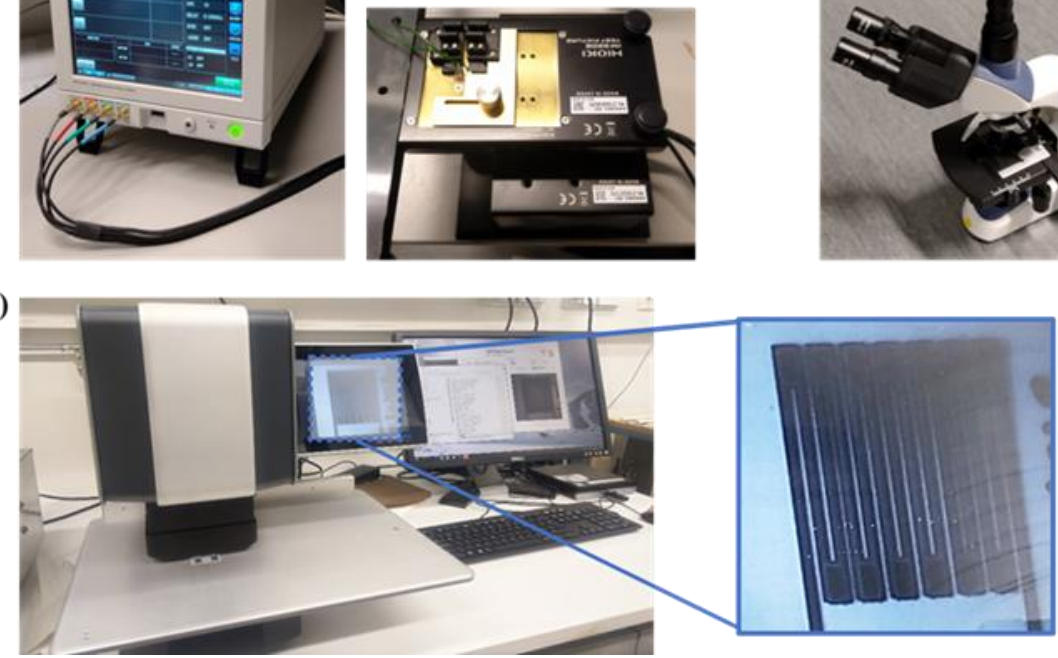

Fig. 2 Printing and measurement devices: (a) Epson Stylus C88+ printer, (b) In-house photonic curing device, (c) HIOKI IM7587 impedance analyzer and IM9202 test fixture, (d) light microscope equipped with 6.3 MP Swiftcam digital camera, (e) height measurement for printed traces with L\&W Optitopo system

In order to characterize the conductivity and formulate an optimal printing process, strain gauges were fabricated with one, two and three printed layers, i.e. passes over the same pattern. Moreover, a custom photonic curing system with $1500 \mathrm{~W}$ flash device was also assembled, the components of which were purchased from Xenon Flash Tubes LLC (www.xenonflashtubes.com), and implemented to sinter AgNPs for approximately 15 seconds immediately after the printing process was over for each layer. The microscopic structure investigations and $R_{0}$ measurements (as later provided in Results section) were thereafter carried out. For $R_{0}$ measurements, TENMA 72-7745 multimeter was used while 6.3 MP Swiftcam microscope digital camera apparatus was used for the microscopic analysis. In order to measure the printed trace height and generate the height maps, L\&W Optitopo surface roughness measurement device was used as depicted in Fig. 2. By means of this device, a pattern of shadows was created by illuminating the sample surface from a small angle. Then, by utilizing two images of the same area illuminated from opposite sides, the height maps for the printed strain gauges were generated in $\mu \mathrm{m}$ scale. The 
measurement area was taken as $32 \mathrm{~mm} \times 32 \mathrm{~mm}$, which is the maximum range achieved with L\&W Optitopo, and the resolution and bandpass were $15.625 \mu \mathrm{m}$ and 0.01-0.5 mm, respectively. In order to analyze the height uniformity, the height profiles were measured over rows (top-center-bottom) on the grids of the printed strain gauges.

\subsection{Experiment Setup and Measurement System for Characterization}

In order to evaluate the performance and understand the characteristics of the printed strain gauges, a slender cantilever beam as schematized in Fig. 3 was built so that only bending moments (eliminating the shear) were taken to be the dominant source of deformation. Here, $l$ is the distance between the fixed end and applied load $F ; x, b$ and $h$ are the distance between the fixed end and strain gauge center, beam breadth and height, respectively. At the free end of the beam, a 3D printed plate was attached with a single screw to provide an easy way of applying load $F$ at the specified distance $l=390 \mathrm{~mm}$. For this purpose, a set of calibration weights was used, and deflections, strains and electrical characteristics of the printed strain gauges and the commercial reference gauges (RS PRO $4 \mathrm{~mm} 120 \Omega$ metallic foil strain gauge with the gauge factor $G F=2$ ) at two different beam locations, $x=120 \mathrm{~mm}$ and $170 \mathrm{~mm}$, were measured (please, see Fig.3).

(a)

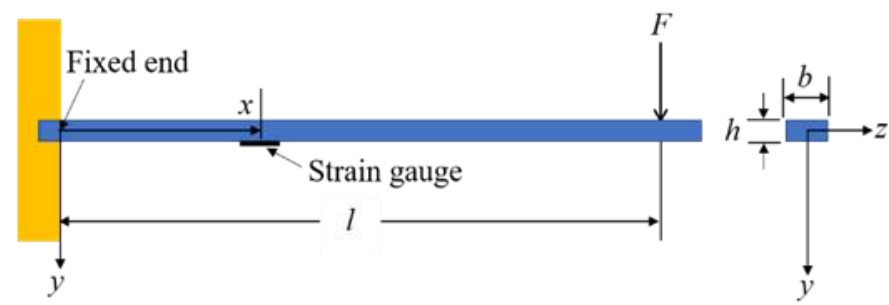

(b)

Digital Dial

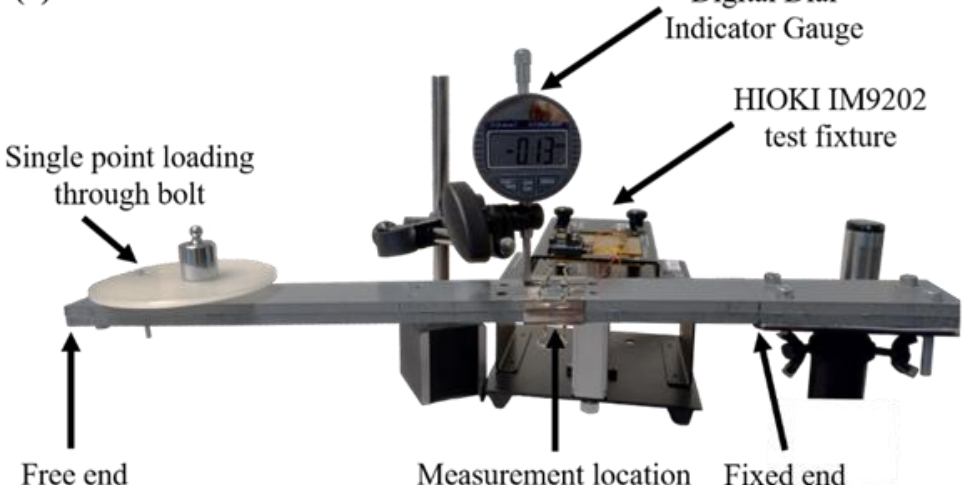

Free end

Measurement location Fixed end

Fig. 3 Cantilever beam: (a) schematic diagram, (b) setup with the test fixture and digital dial indicator gauge

The conductive pads of the printed strain gauges were firmly attached to $10 \mathrm{~cm}$ wires with conductive copper tape. Thereafter, the strain gauges were taped to the measurement location $x$ and pressed with a support plate in order to have a firm grip of the strain gauge and provide correct bending and stretch/contraction over it. The wires were then connected to a Hioki IM9202 test fixture as shown in Fig. 2(c), which was then connected to IM9201 test head used by the Hioki IM7587 impedance analyzer for measuring $R$ and $Z$ of the strain gauge. The measurements were carried out by sweeping a signal frequency 
range of 1-120 MHz with LCR-mode on, which was repeated ten times to obtain the average and the standard deviation. The shortest possible frequency interval of $0.1 \mathrm{MHz}$ provided by the device was used while samples were taken with the impedance analyzer application provided by Hioki capable of sweeping and saving the data as .csv file. In all the tests, applied load $F$ was adjusted in order to provide the beam deflections of $\delta=\{0,0.3,0.6,0.9$, $1.2,1.5,1.8,2.1,2.4\} \mathrm{mm}$ with a tolerance of $\pm 0.05 \mathrm{~mm}$ at the measurement locations, which were later converted into strains $\varepsilon$ by using the formula sets provided in the Appendix. As shown in Fig. 3, an RS Pro electronic digital indicator gauge with $\pm 0.02 \mathrm{~mm}$ accuracy and $25 \mathrm{~mm}$ range were used for the deflection measurements.

\section{Results and Discussion}

\subsection{Effects of Printed Layers and Photonic Curing}

In order to understand the conductivity changes with respect to the fabrication parameters and provide repeatable process solutions, a set of measurements were carried out by using $n=10$ printed strain gauges. Through these measurements, the effects of number of printed layers and photonic curing on the printing quality and resistance of strain gauges were analyzed. For this purpose, one, two and three layers of AgNP ink were deposited onto the substrate, respectively, where the sintering was carried out with photonic curing of 1500 W for approximately 15 seconds. The height profiles depicted in Fig. 4 demonstrates that both printed layers and curing have positive effect on the trace height. However, as a negative effect, the increase in number of printed layers caused spreading of the ink; thus, undesired increase in trace width. In addition to the height profile measurements, as seen in the microscope images of Fig. 5, photonic curing combined with multiple layers of printing was also observed to provide more consistent and denser traces. For instance, Fig. 5 (b) for one layer of print without any sintering shows that some of the deposited ink droplets were not connected to the agglomerate. As a result of these unconnected droplets of the printed structure, the resistance was observed to be as high as $R_{0}=157 \pm 5 \Omega$ for the designed and printed strain gauges. However, after printing and curing the second layer, there was a drastic reduction in the resistance of $R_{0}=65 \pm 2 \Omega$ on average, which continued to drop to $R_{0}=45 \pm 1 \Omega$ on average with additional third layer and photonic curing (please, see Fig. 5 (f)). Interestingly, the resulting resistance of three-layer strain gauge is close to $50 \Omega$ that is common standard for matching different circuits [25]. In addition, the effect of adding more than three layers on the conductivity was obtained to be negligible; thus, three printed layers with photonic curing was taken as the fabrication parameters for the present designed strain gauges.

(a)

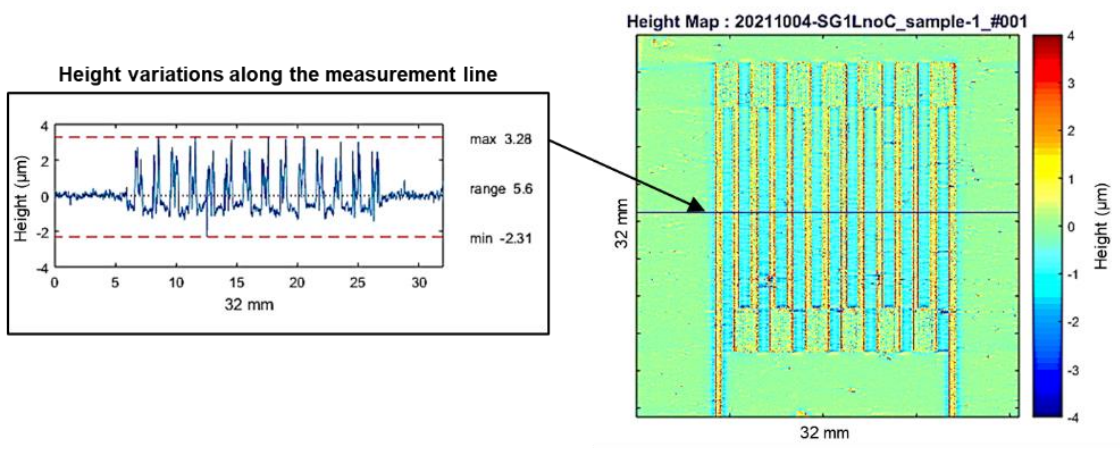

, 

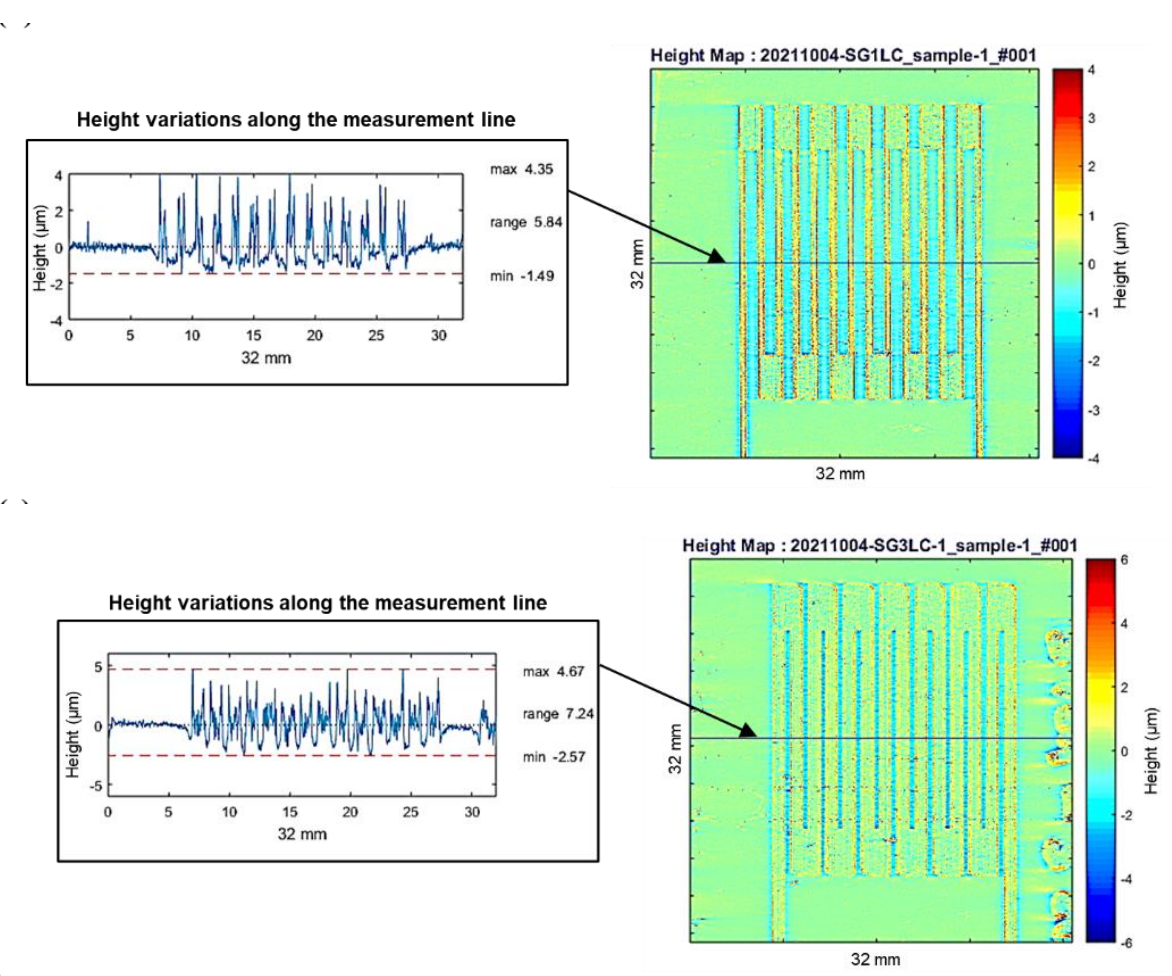

Fig. 4 Effect of printed layers and curing on the strain gauge height profiles: (a) one layer of print no curing (maximum value of $3.28 \mu \mathrm{m}$ ), (b) one layer of print with curing (maximum value of $4.35 \mu \mathrm{m}$ ), (c) three layers of print with curing after each layer (maximum value of $4.67 \mu \mathrm{m}$ ). The scanned area is $32 \mathrm{~mm} \times 32 \mathrm{~mm}$ while the height profiles are represented in $\mu \mathrm{m}$ scale, which were obtained by scanning the center rows of the strain gauge grids

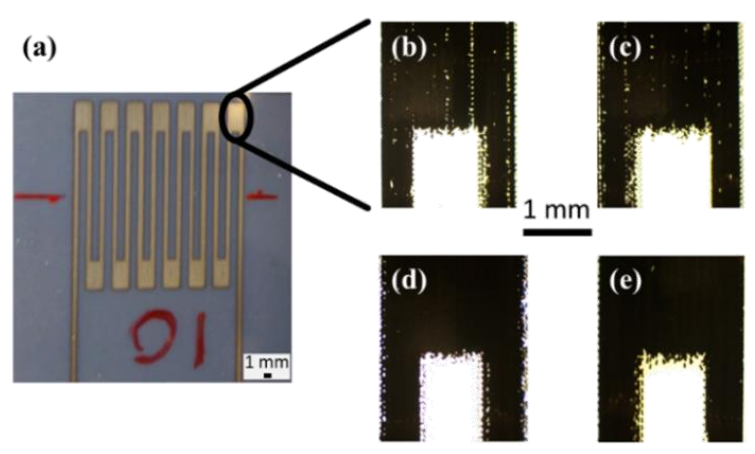




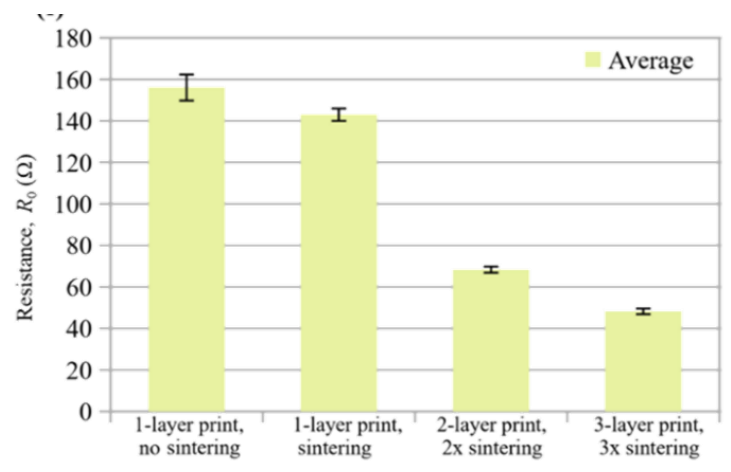

Fig. 5 Printed strain gauge and light microscope images showing the morphological changes due to photonic curing and number of printed layers: (a) digital still, (b) light microscope image for one layer of print without photonic curing, (c) one layer of print and photonic curing, (d) two layers of print and photonic curing, (e) three layers of print and photonic curing, (f) impact of multiple layers and curing on the ohmic resistance R0 of printed strain gauge

\subsection{Gauge Factor $G F$}

(a)

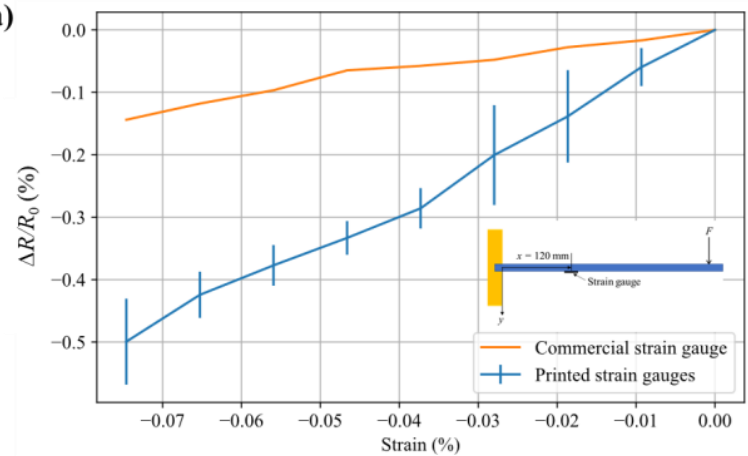

(b)

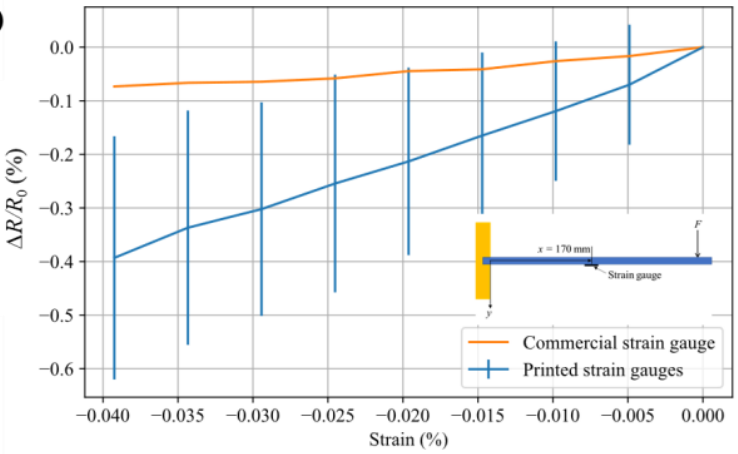

Fig. 6 Resistance change $\Delta R$ with respect to $R_{0}$ of the printed strain gauges as a function of strain within the $49-50 \mathrm{MHz}$ bandwidth: (a) at $x=120 \mathrm{~mm}$ and (b) at $x=170 \mathrm{~mm}$. Error bars refer to the standard deviation while the straight lines represent the mean values 
In order to investigate the accuracy of the built setup and determine the $G F$ of the printed strain gauges, measurements were carried out at two different locations on the cantilever beam, i.e. $x=120 \mathrm{~mm}$ and $x=170 \mathrm{~mm}$ (please, see Fig. 6). As the initial step, frequency bandwidth was set to $49-50 \mathrm{MHz}$ for $G F$ measurements because of great impedance variations near $\omega_{r} \sim 200 \mathrm{MHz}$ (as elaborated in the following sections). The chosen range provided stable results for $G F$ and beam deflection-impedance correlation.

For the measurement setup and device validation, the measurements were conducted by using the commercially available metallic foil strain gauges with the provided $G F=2$ by the manufacturer datasheet. The measurements at different locations were conducted one time with the commercial strain gauges while they were repeated 10 times for the printed strain gauges fabricated using three layers and photonic curing process. As a result of the measurements with the commercial strain gauges, $G F$ was obtained as $\sim 1.8$, showing $10 \%$ measurement setup and device error. For the printed strain gauges, $G F=6.6 \pm 0.3$ and $G F=6.6 \pm 0.9$ were measured for $x=120 \mathrm{~mm}$ and $x=170 \mathrm{~mm}$, respectively. This demonstrates that the printed strain gauges provide repeatable results at different measurement locations with varying beam deflections. It is also noteworthy that the printed strain gauges were obtained to have higher sensitivity when compared with the commercial strain gauge measurements. This also shows the application potentials of the the printed strain gauges, e.g. in detecting tiny vibrations and daily movements of the human body, which can be cumbersome with the conventional gauges [26].

\subsection{Impedance $Z$ and Frequency Dependency}

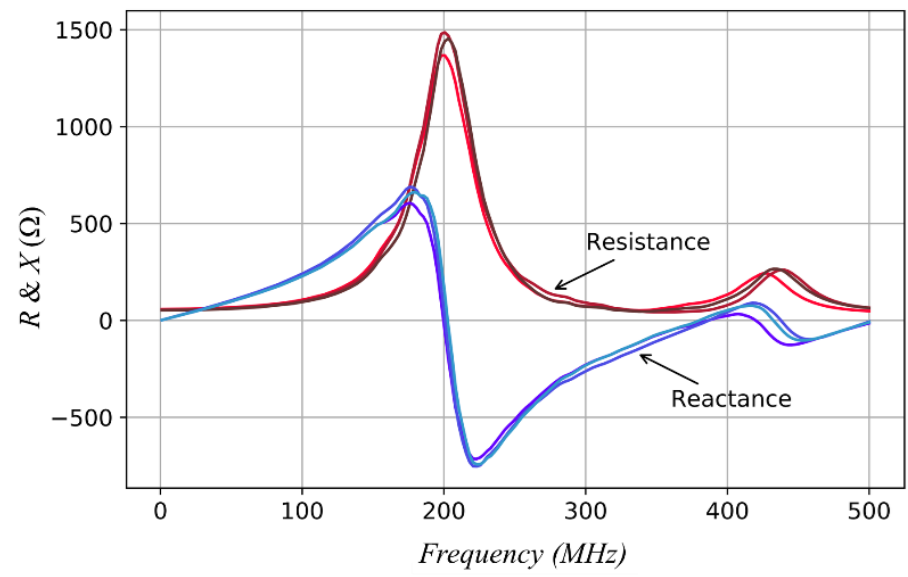

Fig. 7 Resistance $R$ and reactance $X$ measurements for three printed strain gauges in unloaded initial configuration, i.e. no bending

The resistance and reactance of the printed strain gauges are depicted in Fig. 7. All three strain gauges have relatively close frequency responses with $\omega_{r}$ around $200 \mathrm{MHz}$. At $\omega_{r}$, the resistance is at its highest value while the reactance changes the phase, which brings forth the impact of the fabrication/printing related differences. As seen in Fig. 7, close to $\omega_{r}$, all the fabrication/printing originated variations are amplified, which makes it more difficult to control the uniformity of the strain gauge behaviour. On the other hand, all the strain gauge have relatively close behaviour well below $\omega_{r}$.

In Figs. 8a and 9a, resistance change $\Delta R$ and reactance change $\Delta X$ of a printed strain gauge, which can be elaborated as the differences between the values measured for deformed configuration caused by $\varepsilon$ and initial configuration, are provided for $800 \mathrm{MHz}$ bandwidth. Below $\omega_{r}, \Delta R$ has negative dependency while above it is vice versa. The closer the frequency 
is to $\omega_{r}$, the higher is the $\varepsilon$ sensitivity. Besides, as seen in Fig. 7, variances between the different gauges were observed to be amplified at around $\omega_{r}$. For sufficiently low frequency below $\omega_{r}$, strain gauge resistance has systematic dependency on $\varepsilon$, which is depicted in the magnified portion of Fig $8 \mathrm{~b}$. This indicates that a printed strain gauge does not have to operate only on DC frequency but can also operate on some higher frequency. Around $\omega_{r}$ and above, it was deduced that the printed strain gauge has to be calibrated. Such calibration is needed in order to remove printing related variations between the strain gauges and to identify whether there exists negative or positive $\varepsilon$ dependency at particular frequency.

Nonetheless, the results in Fig. 9a indicate that the printed strain gauges can measure deflections not only by $\Delta R$ but also by $\Delta X$. Interestingly, $\Delta X$ has higher strain sensitivity above $\omega_{r}$. Similar to the $\Delta R$ measurements, the $\Delta X$ frequency response is mostly monotonous below $\omega_{r}$, which was similar to the trend obtained for the $\Delta R$ measurements (please, see Figs. 8b and 9a). However, it is also noteworthy that the $\Delta X$ values of the printed strain gauges subjected to bending were observed to be changing from positive to negative around $45 \mathrm{MHz}$, which requires attention in case of reactance based strain measurements.

(a)

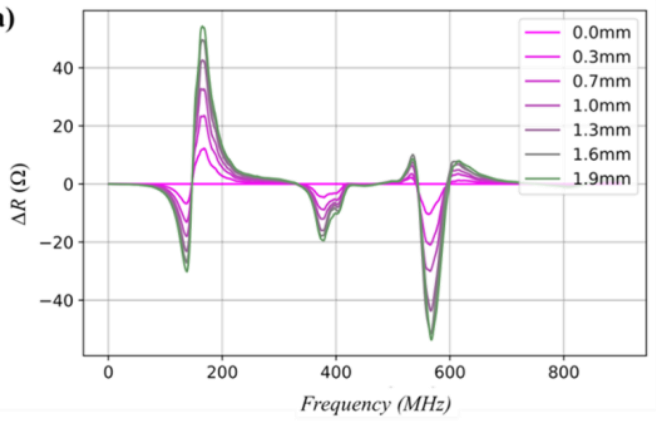

(b)

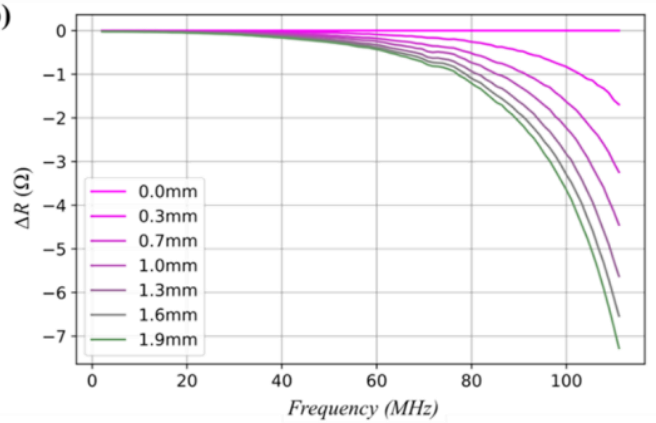

Fig. 8 Resistance change $\Delta R$ of one strain gauge under deflection: (a) the whole measured bandwidth, (b) restrained bandwidth

(a)

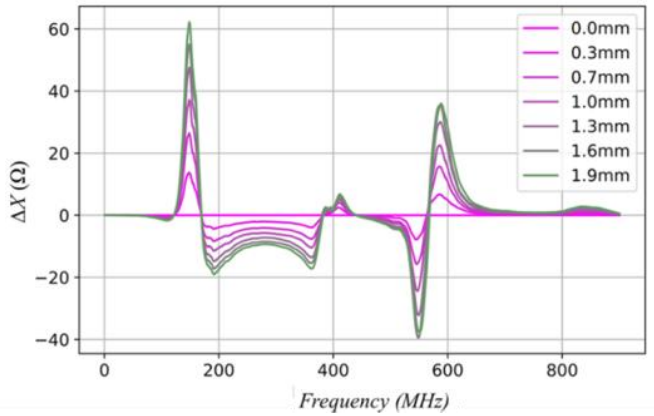

(b)

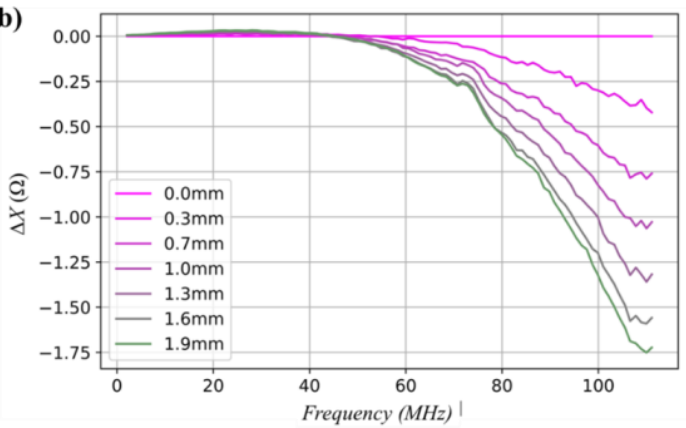

Fig. 9 Reactance change $\Delta X$ of one strain gauge under deflection: (a) the whole measured bandwidth, (b) restrained bandwidth

In addition to the printed strain gauges, comparative frequency dependent investigations for $\Delta R$ and $\Delta X$ was also carried out with commercially available strain gauges, the plots of 
which are presented in Fig. 10. For these particular strain gauges, the range of bending dependency was obtained to be in much more smaller range than the one for the printed strain gauges. Similar to the printed strain gauges, the results for the commercial strain gauges in Fig. 10 indicates that there is negative bending dependency of both $\Delta R$ and $\Delta X$.
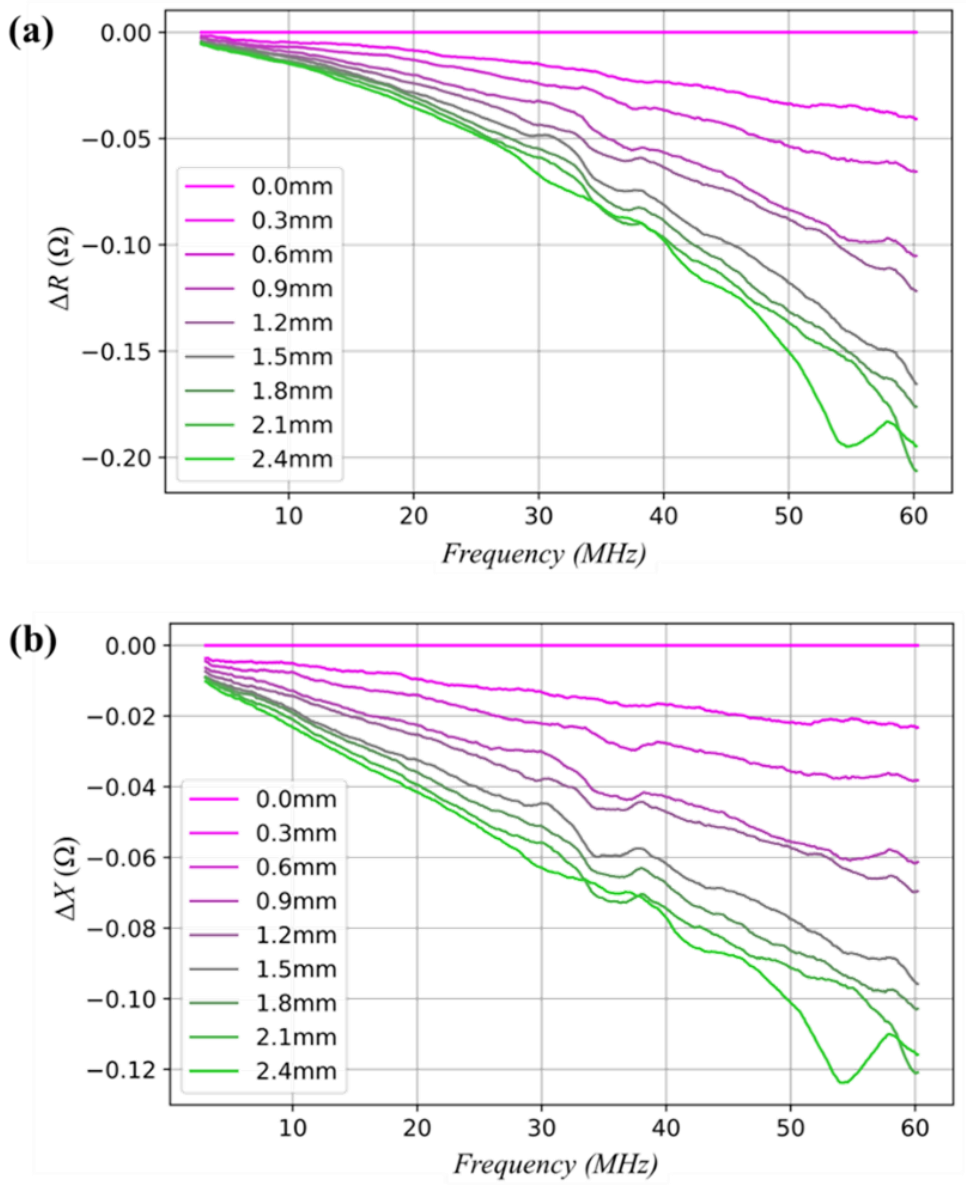

Fig. 10 Commercial strain gauge at $\mathrm{x}=170 \mathrm{~mm}$ position: (a) resistance change $\Delta \mathrm{R}$, (b) reactance change $\Delta \mathrm{X}$

\section{Conclusions}

The present study provided a framework for the fabrication and characterization of lowcost inkjet-printed strain gauges, $\Delta R$ and $\Delta X$ of which vary with the applied load $F$ and frequency $\omega$. For this purpose, AgNP inks and coated PET substrates manufactured by Mitsubishi Papermills were investigated with a focus on the effect of number of printed layers and curing on the DC resistance $R_{0}$. As a result of this investigation on the fabrication process, the printing parameters such as number of printed layers and curing were found out to have positive effects on the conductivity (with reductions in $R_{0}$ ). For instance, one layer printed and non-cured strain gauges were obtained to have $R_{0}=158 \Omega$ on average, while $R_{0}=140 \Omega$ on average was reached after photonic curing, which agglomerates the AgNP and increases the conductivity. Moreover, number of printed layers, thus trace 
height, was another important printing parameter affecting the conductivity. For instance, three printed layers and photonic-cured strain gauges resulted in $R_{0}=45 \Omega$ and $G F \sim 6.6$ (within the frequency bandwidth of $49-50 \mathrm{MHz}$ ) on average, which was obtained to be slightly higher than the $G F$ values for the strain gauges fabricated with similar inkjet printing strategies in the literature. Therefore, these affordable and easy-to-design printed strain gauges can be an alternative to the commercially available ones with similar dimensions but higher resistance $\left(R_{0}=120 \Omega\right)$ and lower gauge factors $(G F=2)$. Another important outcome of the printed strain gauges was their electromagnetic characteristics investigated in terms of impedance over a large frequency range up to $800 \mathrm{MHz}$. It was deduced that they can function as resonant (LC) circuit with their specific resonant frequencies $\omega_{r}$. Therefore, they can be used as flexible and tailorable solutions for remote sensing and structural monitoring, such as in biomedical, seismic or aviation applications, through which the use of heavy-wiring can be minimized. As future studies, degradation and temperature dependency under various operational conditions will be also investigated, which makes such sensors to be robustly utilized in thermal sensing applications such as battery and indoor air temperature monitoring.

\section{Acknowledgement}

The authors gratefully acknowledge the funding from Academy of Finland BESIMAL project (decision number 334197). J.W. also acknowledges the funding from Jenny and Antti Wihuri Foundation. Besides, the authors acknowledge the technical assistance of Timi Lehtola and Juhapekka Hietala.

\section{References}

[1] KT, Watkins JK, Phero T, Litteken D, Tsai K, Bingham T, Ranganatha KL, Johnson BC, Deng Z, Jaques B, Estrada D. Aerosol jet printed capacitive strain gauge for soft structural materials. npj Flexible Electronics, 4:2397-4621, 2020. https://doi.org/10.1038/s41528-020-00095-4

[2] Mitterlehner T, Beisteiner C, Polixmair M, Steinbichler G. Injection molding parts with integrated all-inkjet printed strain gauge for condition monitoring. In ANTECÂ 2018 Proceedings of the Technical Conference \& Exhibition, Orlando, FL, May 7-10, 2018. Society of Plastics Engineers, 2018.

[3] Yi Y, Wang B, Bermak A. A low-cost strain gauge displacement sensor fabricated via shadow mask printing. Sensors, 19(21):4713, 2019. https://doi.org/10.3390/s19214713

[4] Kim J, Kim K, Ham SW, Bae NH, Park MY, Min NK. A hydrogen pressure sensor based on bulk-micromachined silicon strain gauges. Procedia Engineering, 168:790-793, 2016. https://doi.org/10.1016/i.proeng.2016.11.260

[5] Shakeel M, Khan WA, Rahman K. Fabrication of cost effective and high sensitivity resistive strain gauge using DIW technique. Sensors and Actuators A: Physical, 258:123-130, 2017. https://doi.org/10.1016/j.sna.2017.03.003

[6] Thompson B, Yoon HW. Aerosol-printed strain sensor using PEDOT:PSS. IEEE Sensors Journal, 13(11):4256-4263, 2013. https://doi.org/10.1109/ISEN.2013.2264482

[7] Andò B, Baglio S, La Malfa S, L'Episcopo G. All inkjet printed system for strain measurement. In Sensort, 2011 IEEE, pages 215-217. IEEE, 2011. https://doi.org/10.1109/ICSENS.2011.6127295

[8] Mantysalo M, Pekkanen V, Kaija K, Niittynen J, Koskinen S, Halonen E, Mansikkamaki P, Hameenoja O. Capability of inkjet technology in electronics manufacturing. In 59th Electronic Components and Technology Conference, pages 1330-1336. IEEE, 2009. https://doi.org/10.1109/ECTC.2009.5074185 
[9] Ando B, Baglio S. All-inkjet printed strain sensors. IEEE Sensors Journal, 13(12):48744879, 2013. https://doi.org/10.1109/ISEN.2013.2276271

[10] Wiklund J, Karakoç A, Palko T, Yiğitler H, Ruttik K, Jäntti R, Paltakari J. A review on printed electronics: Fabrication methods, inks, substrates, applications and environmental impacts. Journal of Manufacturing and Materials Processing, 5(3):89, 2021. https://doi.org/10.3390/jmmp5030089

[11] Cummins G, Desmulliez MPY. Inkjet printing of conductive materials: a review. Circuit World, 38(4):193-213, 2012. https://doi.org/10.1108/03056121211280413

[12] Özkan M, Dimic-Misic K, Karakoc A, Hashmi SG, Lund P, Maloney T, Paltakari J. Rheological characterization of liquid electrolytes for drop-on-demand inkjet printing. Organic Electronics, 38:307-315, 2016. https://doi.org/10.1016/i.orgel.2016.09.001

[17] Özkan M, Hashmi SG, Halme J, Karakoc A, Sarikka T, Paltakari J, Lund PD. Inkjetprinted platinum counter electrodes for dye-sensitized solar cells. Organic Electronics, 44:159-167, 2017. https://doi.org/10.1016/j.orgel.2017.02.015

[14] Roshanghias A, Krivec M, Baumgart M. Sintering strategies for inkjet printed metallic traces in 3d printed electronics. Flexible and Printed Electronics, 2(4):045002, 2017. https://doi.org/10.1088/2058-8585/aa8ed8

[15] Kuroda K, Nakako H, Inada M, Noudou T, Kumashiro Y. Development of copper materials and processing for printed electronics. Transactions of The Japan Institute of Electronics Packaging, 5(1):20-25, 2012. https://doi.org/10.5104/jiepeng.5.20

[16] Saleh E, Vaithilingam J, Tuck C, Wildman R, Hague R, Ashcroft I, Dickens P. 3d inkjet printing of conductive structures using in-situ IR sintering. In Proceedings of the 26th Annual International Solid Freeform Fabrication Symposium, pages 1554-1559. University of Texas, 2015.

[17] German RM. Thermodynamics of sintering. In Sintering of advanced materials, pages 3-32. Elsevier, 2010. https://doi.org/10.1533/9781845699949.1.3

[18] Kitzing H. A solid base for precision strain gauge measurements. In Proceedings of XVI. IMEKO World Congress, Vienna, Austria, pages 405-408, 2000.

[19] Heckmann U, Bandorf R, Gerdes H, Lübke M, Schnabel S, Bräuer G. New materials for sputtered strain gauges. Procedia Chemistry, 1(1):64-67, 2009. https://doi.org/10.1016/i.proche.2009.07.016

[20] Rahman MT, Moser R, Zbib HM, Ramana CV, Panat R. 3d printed high performance strain sensors for high temperature applications. Journal of Applied Physics, 123(2):024501, 2018. https://doi.org/10.1063/1.4999076

[21] Kravchuk 0, Reichenberger M. Properties and long-term behavior of nanoparticle based inkjet printed strain gauges. Journal of Materials Science: Materials in Electronics, 27, 2016. https://doi.org/10.1007/s10854-016-5207-9

[22] Bona M, Sardini E, Serpelloni M, Andò B, Lombardo CO. Study on impedance behavior of a telemetric system operating with an inkjet-printed resistive strain gauge. In Bruno Andò, Francesco Baldini, Corrado Di Natale, Giovanna Marrazza, and Pietro Siciliano, editors, Sensors, pages 258-266, Cham, 2018. Springer International Publishing. https://doi.org/10.1007/978-3-319-55077-0_34

[23] Bona M, Sardini E, Serpelloni M, Andò B, Lombardo CO. Study on a telemetrie system that works with an inkjet-printed resistive strain gauge. In 2016 IEEE Sensors $\begin{array}{llll}\text { Applications } & \text { Symposium } & \text { (SAS), } & \text { pages }\end{array}$ https://doi.org/10.1109/SAS.2016.7479869

[24] Cheng X, Yu Y, Wang L, Sun C, Tian G. Wireless stress measurement on metal surface based on passive integrated rfid sensor tag. In 2021 IEEE International Instrumentation and Measurement Technology Conference (I2MTC), pages 1-6. IEEE, 2021. https://doi.org/10.1109/I2MTC50364.2021.9460006

[25] Yarman BS. A simplified real frequency technique for broadband matching complex. IIMBO, 43:529, 1982. 
[26] Yan W, Fuh HR, Lv Y, Chen KQ, Tsai TY, Wu YR, Shieh TH, Hung KM, Li J, Zhang D, Coileáin CÓ, Arora SK, Wang Z, Jiang Z, Chang CR, Wu HC. Giant gauge factor of Van der Waals material based strain sensors. Nature communications, 12(1):1-9, 2021. https://doi.org/10.1038/s41467-021-22316-8

[27] Young WC, Budynas RG, Sadegh AM. Roark's formulas for stress and strain. McGrawHill Education, 2012.

\section{Appendix}

Based on the provided annotations for cantilever beam geometry and applied point load in Fig. 3, the relationship between the beam deflection and strain at the strain gauge location can be expressed as follows [27]:

Deflection at the strain gauge location $x \in \mathrm{R}^{+}$

$$
\delta=\frac{P x^{2}}{6 E I}(3 l-x)
$$

Point load in terms of deflection

$$
P=\delta \frac{6 E I}{x^{2}(3 l-x)}
$$

Stress at $\mathrm{x}$

$$
\sigma=\frac{M y}{I}=\frac{P(l-x) y}{I}=P \frac{(l-x) h}{2 I}
$$

Stress in terms of deflection

$$
\sigma=\delta \frac{3 E}{x^{2}(3 l-x)}(l-x) h
$$

Stress-strain relationship (assuming linear elasticity)

$$
\varepsilon=\frac{\sigma}{E}
$$

Strain in terms of deflection

$$
\varepsilon=\delta \frac{3}{x^{2}(3 l-x)}(l-x) h
$$

